\title{
BOLETIM INFORMATIVO \\ DO DEPARTAMENTO DE ESTRUTURAS \\ DO CENTRO DE TECNOLOGIA DA UFPI: \\ UMA ESTRATÉGIA DE LEGITIMAÇÃO
}

\section{Information bulletin of the Department of Structures of the Technology Center of the UFPI: a legitimation strategy}

\author{
Magnaldo de Sá CARDoso \\ Centro de Ensino Unificado do Piani-CEUPI \\ Correo-e:magnaldo@ufpi.edu.br \\ Maria do Amparo Borges Ferro \\ Universidade Federal do Piani-UFPI \\ Correo-e: amparoferro@uol.com.br \\ Recepción: 5 de julio de 2018 \\ Envío a informantes: II de julio de 2018 \\ Aceptación definitiva: 2 de octubre de 2018
}

Resumen: En la Universidad Federal de Piauí (Brasil), dentro de su Departamento de Estructuras, creado en 1975 , se publica el Boletim informativo do Departamento, del Centro de Tecnología, desde 1985 como un instrumento de legitimación científica y profesional. En el artículo se estudian la estructura y los contenidos de sus inicios.

Palabras clave: Prensa pedagógica; Universidad Federal do Piauí (Brasil); Boletín; Tecnología.

Aвstract: At the Federal University of Piauí (Brazil) within its Department of Structures, created in 1975, the Boletim informativo do Departamento, from the Technology Center is published, since 1985 as an instrument of scientific and professional legitimization. In the article the structure and contents of its beginnings are studied.

Key words: Pedagogical Press; Federal University of Piauí (Brazil); Bulletin; Technology. 


\section{Considerações iniciais}

$\mathrm{E}$ STE TRABALHO APRESENTA UM ESTUdO sobre a publicação do Boletim Informativo do Departamento de Estruturas e sua influência no processo político de escolha de diretores para o Centro de Tecnologia (Ст) da Universidade Federal do Piauí (UfPI).

O Centro de Tecnologia, foi implantado através da Resolução n. ${ }^{\circ} 38$ do Conselho Universitário, a 25 de agosto de 1975 , inicialmente constituído pelas Coordenações de Ciências Agrárias e de Tecnologia. A partir do ano de 1978, houve o desmembramento da Coordenação de Ciências Agrárias dando origem aos Centros de Ciências Agrárias e de Tecnologia, este último estruturado em novos cursos e novos departamentos.

Com o lançamento do impresso o então Chefe do Departamento de Estruturas, candidato ao cargo de Diretor, acreditava reunir as condições de levar à frente uma abertura política no Ст, contra a posse ao cargo por indicação. Sendo assim, sinalizou que passaria os quatro anos seguintes trabalhando a ideia de sua candidatura. Surgem, a partir daí as estratégias de legitimação de uma proposta de campanha política, com destaque para a publicação do Boletim Informativo.

Desse modo, é que se propõe, neste artigo de uma análise da primeira edição do Boletim Informativo do Departamento de Estruturas do CT/UFPI-Brasil, de junho I985, tomando como base a legitimação de uma proposta de campanha política presente neste documento, mais especificamente ao cargo de Diretor e Vice-Diretor, quadriênio 1989/1992, deste Centro de Ensino.

Complementando a edição, na contracapa do Boletim encontram-se dois parceiros patrocinadores: a EMPOL- Eletrometalúrgica Poty Ltda, fabricante de móveis de aço, estantes e equipamentos elétricos e a Construtora Poty Ltda com os serviços de Cálculos, Construção Civil, Consultoria e Projetos.

Nessa perspectiva, vale ressaltar Catani (20I3), sobre a importância de se produzir conhecimentos especializados para formar e orientar o exercício da docência, que, em nosso estudo,

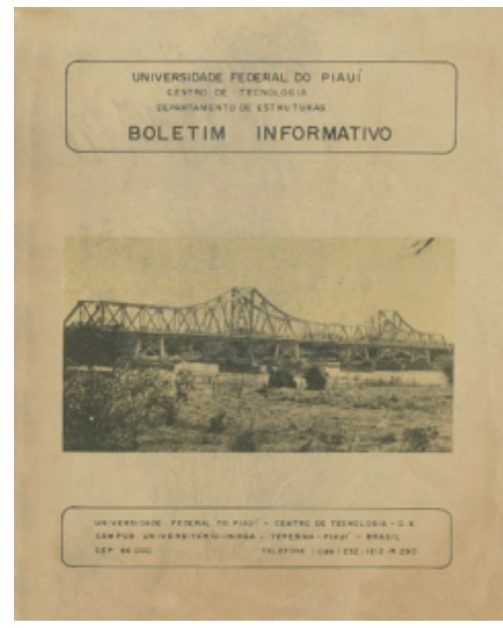

FOnTE: Arquivos próprios do pesquisador ${ }^{\mathrm{I}}$.

A foto da capa do Boletim destaca a Ponte Metálica João Luiz Ferreira, sobre o Rio Parnaíba, que liga as cidades de Teresina, Capital do Estado do Piauí à vizinha cidade de Timon no Estado do Maranhão. Esta ponte foi a primeira obra construída sobre o Rio Parnaíba ligando os Estados do Piauí e Maranhão. 
BOLETIM INFORMATIVO DO DEPARTAMENTO DE ESTRUTURAS DO CENTRO DE TECNOLOGIA DA UFPI: UMA ESTRATÉGIA DE LEGITIMAÇÃO MAGNALDO DE SÁ CARDOSO Y MARIA DO AMPARO BORGES FERRO

recai sobre a produção de Boletins Informativos Oficiais, e das ideias de Fávero (2000), quando ressalta a importância do pesquisador na abordagem e interpretação desses documentos, uma vez que estes, sozinhos, não falam por si, daí a necessidade de o pesquisador compreender o pensamento que há por detrás deles, ancorado em uma base teórica.

Como pontua Catani (2013: II9) «a questão de conhecer as leituras dos professores e as estratégias de legitimação e imposição de certas representações de autores [...]» é uma das relevâncias da utilização de tal documento como fonte.

Desse modo, é que este intento investigativo partiu da seguinte problematização: De que forma os créditos das matérias publicadas no Boletim Informativo/1985 da UFPI agregam valores no processo que busca legitimar a candidatura a Diretor deste Centro de Ensino?

Como contribuição, este estudo, vem ressaltar a importância que este gênero Boletim Informativo teve na formação continuada e na prática de ensino do corpo docente deste Centro de Tecnologia, pois, como releva Nunes (1990), interpretar documentos é traduzi-los, e esta tradução está inserida num horizonte finito, num terreno de pré-compreensões, cujo alargamento não se dá apenas pela vontade do sujeito do pesquisador, mas pelo avanço e rumos que assume o conjunto da produção no qual o seu trabalho se insere.

Para melhor compreensão de como se constitui este estudo, é que organizou-se o texto em três seções: na primeira, há abordagem sobre o recorte temporal da publicação do Boletim Informativo, o movimento nacional de abertura política no Brasil na década de 1980; para em seguida, formular-se um paralelo entre os docentes autores do Boletim e os demais docentes do Centro de Tecnologia de outras áreas de Engenharia não presentes no impresso. Por último, apresenta-se o legado que a iniciativa de publicação do periódico deixou como influência na formação continuada e na prática de ensino do corpo docente do CT/UFPI.

\section{A publicação do Boletim Informativo}

A reestruturação do Centro de Tecnologia, surgiu após a publicação da Resolução n. ${ }^{\circ} 38$ de 25 de agosto de 1975, instituída na época, pelo então Reitor da UfPI e Presidente do Conselho Universitário o Magnífico Reitor José Camillo da Silveira Filho, constituído, inicialmente, pelas Coordenação de Ciências Agrárias e Coordenação de Tecnologia.

Todavia, foi a partir do ano de 1978, que houve o desmembramento da Coordenação de Ciências Agrárias dando origem aos Centros de Ciências Agrárias e de Tecnologia, este último estruturado em novos cursos e novos departamentos.

Segundo Cardoso (2017), o recorte temporal de 1975 a 1978, compreende desde a criação até o desmembramento da Coordenação de Ciências Agrárias. Como bem pontua o autor, este é o momento em que o Cт se assume como «[...] independente e responsável, exclusivamente, pelo ensino de graduação de cursos nas áreas de Tecnologia» (p. 33). O autor explicita ainda a implantação dos departamentos de Construção Civil, Estruturas e Transportes, como também os cursos de Tecnólogo em Construção Civil, Engenharia de Agrimensura e Engenharia Civil. 
BOLETIM INFORMATIVO DO DEPARTAMENTO DE ESTRUTURAS DO CENTRO DE TECNOLOGIA DA UFPI: UMA ESTRATÉGIA DE LEGITIMAÇÃO MAGNALDO DE SÁ CARDOSO Y MARIA DO AMPARO BORGES FERRO

RESOLUÇÃO N. ${ }^{\circ}$ I $8 / 78$

CONSELHO DIRETOR DA FUNDAÇÃO

Dispõe sobre a reestruturação do Centro de Tecnologia e dá outras providências.

O Presidente da Fundação e Reitor da Universidade Federal do Piauí no uso de suas atribuições, tendo em vista decisão do Conselho Diretor e da Fundação em reunião de I5.03.78, e considerando:

- O disposto no art. I8 do Estatuto da Fufpi (Decreto n. ${ }^{\circ}$ 68.53I de I8.05.7I);

- Criação do Centro de Ciências Agrárias que absorveu a Coordenação de Ciências Agrárias do Centro de Tecnologia.

RESOLVE:

I. Extinguir a Coordenação de Tecnologia criada através da Resolução n. ${ }^{\circ}$ 38/75.

2. Criar no Centro de Tecnologia (Ст) os Departamentos de:

- Construção Civil

- Estruturas

- Transportes

3. Instituir as Coordenações do Curso de Engenharia Civil, Agrimensura e do Curso de Curta Duração - Construção Civil: Edifícios.

$[\ldots]$

I8. Esta Resolução entrará em vigor na data de sua publicação, revogadas as disposições em contrário (UFPI, 1978).

Com a nova estrutura, a Diretoria do Ст, passou a funcionar em novas instalações, mais especificamente, nos galpões SG-II e SG-I2, curiosamente conhecido como «Sibéria», pelo fato de estarem localizados nos limites da área do Campus da Ininga, próximo à vegetação nativa existente, remanescente daquela que fora a antiga Fazenda Ininga, onde se ergueram os referidos galpões, necessários para o funcionamento dos cursos já existentes, e de novos cursos que estavam sendo criados. A ideia era que as instalações, naquele primeiro momento provisórias, dariam respaldo ao andamento dos cursos e uma contrapartida para as futuras e definitivas instalações físicas para o $\mathrm{CT}$, o que, aconteceu posteriormente.

A mudança do CT para as novas instalações ocorreu durante o período de 1998 a 2004, com a conclusão definitiva do novo prédio. Durante esse período, a expectativa gerada pela inauguração de novas instalações, motivou todos os segmentos que compunham o Ст, funcionários, alunos, professores, passando-se a especular, discutir, opinar, prever, quais as decisões advindas do Conselho Universitário com a já iminente e definitiva mudança para as novas instalações. Deveria voltar suas ações para a pesquisa e extensão, além do ensino. Propor soluções inovadoras, consistentes e factíveis em uma perspectiva regional, contexto no qual o Centro de Tecnologia está inserido. A mudança passaria também pelo perfil do Diretor do Centro.

\section{O processo de legitimação da campanha para diretor: um diálogo entre autores do Boletim e os demais docentes do CT}

Até a década de I980, as transições dos mandatos dos diretores do CT ocorriam pela ascensão do vice-diretor a diretor, escolhidos, até então, em lista tríplice de nomes em eleição indireta. Deste modo, via de praxe, o Vice-Diretor era alçado à condição de Diretor. Conforme depoimento do Prof. Rômulo Gayoso C. Branco: 
BOLETIM INFORMATIVO DO DEPARTAMENTO DE ESTRUTURAS DO CENTRO

DE TECNOLOGIA DA UFPI: UMA ESTRATÉGIA DE LEGITIMAÇÃO

MAGNALDO DE SÁ CARDOSO Y MARIA DO AMPARO BORGES FERRO

[...] estive como Vice-Diretor do professor Rafael de 80 a 84. Acompanhei o professor Rafael naquela luta de sedimentar, consolidar uma estrutura para a Universidade Federal do Piauí e particularmente uma estrutura para o Centro de Tecnologia. [...] O professor Rafael tentava firmar о Ст, criando cursos. Tentamos o curso de Elétrica, de Mecânica e fizemos um projeto para a criação do Laboratório de Informática, futuro Núcleo de Engenharia de Sistemas- NeS.

Próximo ao final do mandato do Prof. Rafael-Victor C. do Rêgo Monteiro, o Conselho Departamental reuniu-se, conforme regulamentação vigente à época, para elaborar a Lista Tríplice com os nomes que seriam encaminhados ao então reitor Dr. Nathan Portella Nunes, para que esse indicasse o Diretor e Vice-Diretor do Centro de Tecnologia. Compunham a lista os professores: José Lages Monte, Antônio Trindade Barros e Rômulo Gayoso Castello Branco.

A indicação recaiu sobre os nomes dos professores José Lages Monte e Antônio Trindade Barros, para Diretor e Vice-Diretor respectivamente. Esse fato consta em depoimento do então indicado a Diretor do cT, prof. José Lages Monte:

[...] em 83 para 84, foi deflagrado o processo para a substituição do professor Rafael-Vitor. [...] naquela época quem escolhia a Lista, era o Conselho Departamental. Encaminhava ao reitor, que então encaminhava ao Ministro da Educação para a escolha do nome.

A Reunião do Conselho Departamental do Centro de Tecnologia para a escolha da Lista Tríplice com os nomes dos professores a serem indicados pelo reitor para ocupar o cargo de Diretor, deu-se de fato em momento muito tenso na comunidade do Centro de Tecnologia. Esse momento é assim registrado pelo Prof. Wilson Martins de Sousa.

Quando da escolha do Prof. Monte, foi uma reunião extremamente tensa, com muita influência da Reitoria com o então Dr. José Nathan Portella. Lembro que a escolha da eleição no CT, envolveu a segurança da UFPI, os conselheiros eram chamados para votar, acompanhados de uma escolta, quase coercitivamente, algo muito estranho. Aquilo mexeu muito conosco, comigo, com o Prof. Rômulo e outros professores. E os estudantes sentiram que era chegado momento de começar a reagir a ações tão policialescas, a gente pode dizer assim.

Como consequência, o fato da indicação do prof. José Lages Monte ao cargo de Diretor do CT, provocou a reação do prof. Rômulo:

[...] eu já estava no processo, e achava que reunia as condições de levar à frente aquela abertura que eu queria para о ст. [...] E me senti alijado, preterido do processo [...] e isso foi de conhecimento público. Também foi público que a partir daquele momento tomei a decisão de ser Diretor do ст. Lutar pra ser. [...] procurei o professor Wilson Martins de Sousa que à época, foi contra o processo indireto [...] e disse a ele que pleiteava fazer um movimento em prol do ст. [...] E passamos quatro anos trabalhando essa ideia.

A partir da nomeação do prof. José Monte para a direção do Centro de Tecnologia, estabeleceu-se um confronto político direto entre dois grupos, nitidamente identificados. Um grupo liderado pela então Diretoria, e a «oposição», que tinham como líderes mais destacados os professores Rômulo Gayoso Castelo Branco e Wilson Martins de Sousa. A elaboração do Regimento Interno do Centro de Tecnologia foi 


\section{BOLETIM INFORMATIVO DO DEPARTAMENTO DE ESTRUTURAS DO CENTRO DE TECNOLOGIA DA UFPI: UMA ESTRATÉGIA DE LEGITIMAÇÃO MAGNALDO DE SÁ CARDOSO Y MARIA DO AMPARO BORGES FERRO}

motivo de debates dos mais acalorados entre os membros do Conselho Departamental. Vivia-se nо ст um ambiente de disputa, porém sempre em defesa dos interesses maiores do Centro.

A partir desse momento acentuou-se o debate de ideias acerca de eleição direta na escolha do próximo Diretor, com a participação dos três segmentos que compunham o Centro de Tecnologia: professores, servidores e alunos. A perspectiva de eleição direta maturava-se, o Prof. Rômulo do Departamento de Estrutura e o Prof. Wilson do Departamento de Recursos Humanos e Geologia Aplicada comungavam pensamentos que se aproximavam.

Os dois Chefes de Departamentos tinham visão contrária ao Diretor em exercício e gozavam de maior penetração entre alunos e servidores com isso, cada vez mais ganhava corpo a ideia de eleições diretas. Assim os dois pretensos candidatos, iniciaram um processo de planejamento e de estratégias prevendo uma disputa futura, caso viesse a consolidar-se as eleições diretas para Diretor e Vice-Diretor do Centro de Tecnologia. Em depoimento o Prof. Wilson relata:

Então, eu e o Rômulo sentamos, para através de um Boletim Informativo mostrar setorialmente o que vinha sendo feito. Começamos a pensar em atividades conjuntas, que mostrasse quem realmente estava fazendo alguma coisa dentro do Centro de Tecnologia. Outros faziam, mas se não tinham um Boletim para informar, ficava a informação centralizada. Mostramos assim, que tínhamos várias oportunidades de ocupar espaços.

Considerando o que Catani (2013: II5) postula de que «a produção de conhecimentos especializados para formar e orientar o exercício da docência se torna mais visível na produção de revistas, manuais de formação, boletins oficiais». E ainda, compreende-se com a autora que, «a questão de conhecer as leituras dos professores e as estratégias de legitimação de certas representações de autores» (p. II9), é que se viu como uma das importantes ferramentas de Legitimação da legitimação da candidatura ao cargo de Diretor e vice-Diretor a utilização do Boletim Informativo como fonte.

Assim, estabeleceu-se uma clara disputa no campo das ideias por espaços de poder em todos os segmentos do Centro de Tecnologia. Por um lado, o Diretor indicado e empossado, do outro uma corrente de pensamentos contrários à gestão vigente compostos de professores que se atribuíam boa penetração entre os segmentos de alunos, servidores e parte dos professores, conhecimento técnico em engenharia e prestígio junto à Administração Superior da Universidade.

A partir da publicação do Boletim Informativo do Departamento de Estruturas, professores liderados pelo Prof. Rômulo consideravam a possibilidade de a partir dessa primeira edição, tomá-la como núcleo informativo de vez que suas características explicitam modos de construir e divulgar o discurso legítimo sobre ensino e o conjunto de prescrições sobre formas ideais de realização do trabalho docente (Catani, 2013). A partir desse momento, deflagrou-se o processo de movimentação política em prol da próxima gestão da diretoria do Centro de Tecnologia da UFPI. 
BOLETIM INFORMATIVO DO DEPARTAMENTO DE ESTRUTURAS DO CENTRO DE TECNOLOGIA DA UFPI: UMA ESTRATÉGIA DE LEGITIMAÇÃO MAGNALDO DE SÁ CARDOSO Y MARIA DO AMPARO BORGES FERRO

4. O Boletim Informativo: influência na formação continuada e na prática de ensino do corpo docente do CT/UFPI

O Boletim Informativo do Departamento de Estruturas do Centro de Tecnologia da Universidade Federal do Piauí, Ano I, n. ${ }^{\circ}$ I de junho de 1985 foi publicado em formato I 48 milímetros por 210 milímetros e continha oito páginas.

$\mathrm{Na}$ Apresentação (p. oI), justifica-se a criação do Boletim da necessidade de se «estabelecer uma ponte de comunicação entre o Departamento de Estruturas -DE, $[\ldots]$ com a comunidade externa ligada à Engenharia Civil». Ressalte-se que, nessa época, o ст abrigava os cursos de Engenharia Civil, Engenharia de Agrimensura e o curso de Tecnólogos em Construção Civil - Edifícios. O Departamento de Estruturas contava «com um corpo docente de dezoito professores, tendo doze professores com curso de pós-graduação, sendo seis em nível de especialização e seis em nível de mestrado».

Em seguida, as Informações Gerais (p. o2), promovem o curso «Projeto Estrutural de Edifícios de Concreto Armado, período de o8 a iz de junho, carga horária 36 horas, ministrante o professor Ricardo Leopoldo e Silva França da Escola Politécnica da Universidade de São Paulo».

Informa que no «segundo período deste ano o DE oferecerá a disciplina optativa Concreto Protendido - 502/430, para alunos de engenharia civil, tendo como ministrante a professora Maria de Lourdes Teixeira Moreira». Destaca que a convite da direção do Complexo Escolar «Bela Vista», o professor Afrânio Piauiense de Sousa proferiu palestra sobre a «Informática na Educação».

Os Cursos de Extensão oferecidos no primeiro período do ano são listados (p.o3), juntamente com a programação de cursos para o segundo período a serem oferecidos "com início em julho próximo».

Às páginas 04 e 05 do Boletim Informativo são apresentados a seção Trabalhos /Teses com a dissertação de mestrado defendida em 15.04.8I, intitulada: Um modelo de Manutenção de Estoque de Matéria-Prima, área de concentração: Engenharia de Sistemas, autor Afrânio Piauiense de Sousa, orientador Professor Dr. Hans Hermar Weber. E conclui com a dissertação de mestrado Análise Estática de Estruturas com Não-Linearidade Física Localizada,
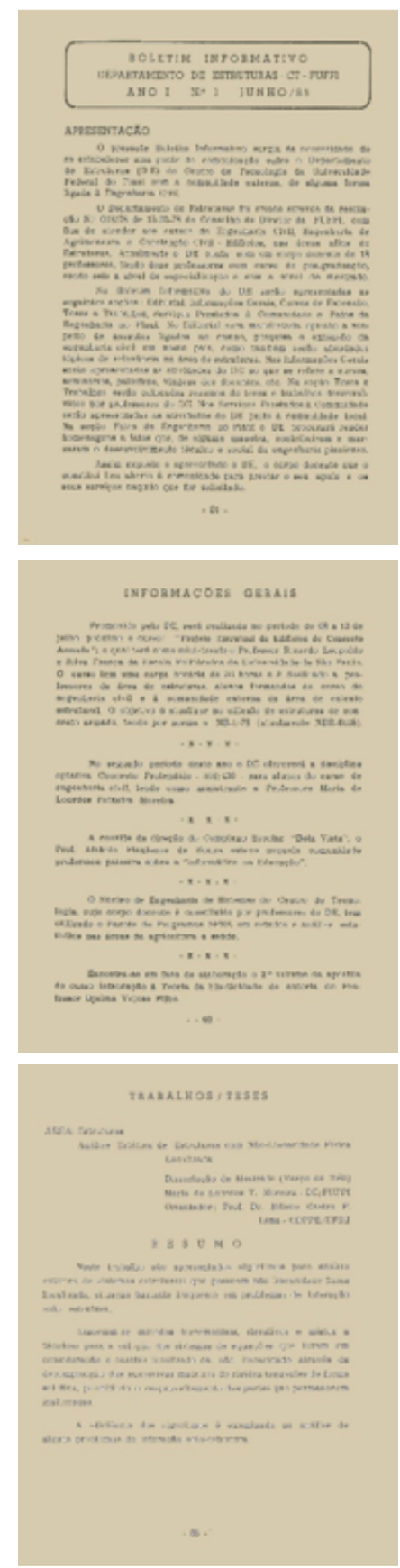

Aula, 25, 2019, pp. 253-26I 
defendida em março de i98I de autoria de Maria de Lourdes T. Moreira tendo como orientador o professor Dr. Edison Castro P. Lima - COPPE/ UFRJ.

Com o título $\mathrm{Fa}$ tos da Engenharia no Pianí (p. o6) de autoria do professor Rômulo G. C. Branco, o texto discorre sobre a montagem da Ponte Metálica, repassando a informação
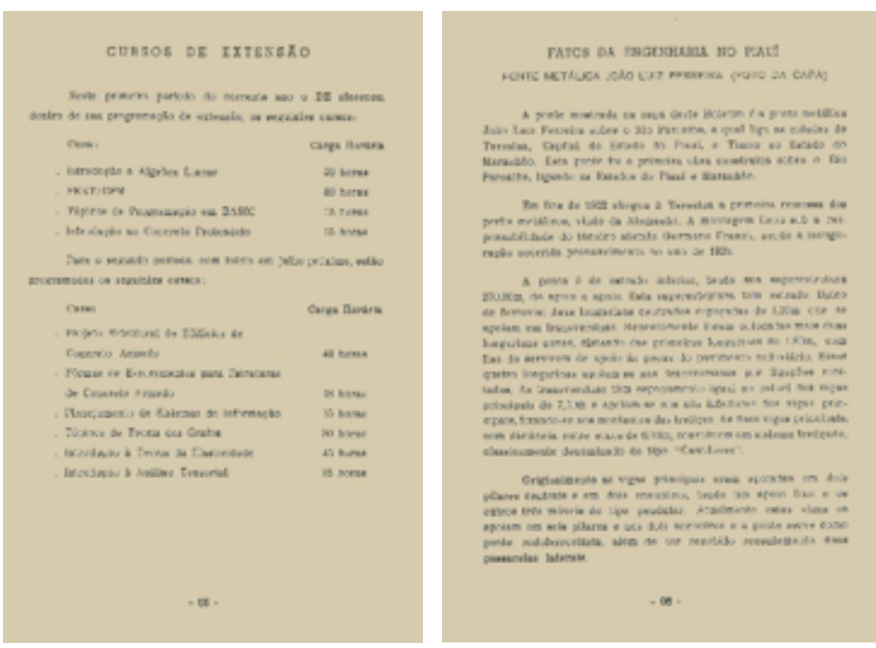
que, «em fins de 1922, chegou a Teresina a primeira remessa dos perfis metálicos, vindo da Alemanha. A montagem ficou sob a responsabilidade do técnico alemão Germano Franck, inauguração ocorrida provavelmente no ano de 1938».

\section{Considerações finais}

Apoiados na conviç̧ão de que reuniam as condições adequadas para ocupar a direção e assim, melhor gerir os destinos do Centro de Tecnologia, o grupo de professores em sua maioria do Departamento de Estrutura e do Departamento de Recursos Hídricos e Geologia Aplicada propunha a redação de um novo Regimento do Conselho Departamental com mais democracia, desta feita com direito a participação através do voto direto os três segmentos da comunidade do Centro de tecnologia: docentes, discentes e servidores técnico-administrativos.

Neste contexto, a Associação dos Docentes da Universidade Federal (ADUfPI), tendo à frente o Prof. José Reis Pereira, sai em defesa de eleições diretas, defendendo uma posição de escolha democrática dos dirigentes dos centros de ensino com a participação de todos os segmentos representativos.

Assim, ao final do mandato do Prof. José Lages Monte, novamente deflagra-se o processo sucessório. Desta vez, como proposta consensual, haveria uma escolha direta dos nomes, uma eleição democrática na qual os candidatos exporiam suas ideias para toda a comunidade do CT, ficando definido, também, que os segmentos de professores, servidores e alunos, fariam parte equitativamente da 
BOLETIM INFORMATIVO DO DEPARTAMENTO DE ESTRUTURAS DO CENTRO

DE TECNOLOGIA DA UFPI: UMA ESTRATÉGIA DE LEGITIMAÇÃO

MAGNALDO DE SÁ CARDOSO Y MARIA DO AMPARO BORGES FERRO

escolha do novo Diretor. Foram eleitos como Diretor e Vice-Diretor os professores Rômulo Gayoso Castello Branco e Wilson Martins de Sousa.

A publicação do Boletim Informativo do Departamento de Estruturas apoiada por professores do Departamento de Recursos Hídricos e Geologia Aplicada contribuiu para a consolidação da campanha política do grupo de professores vitoriosos na eleição direta e democrática no CT, período de 1989 a 1992.

Assim, segundo consta na Apresentação, «o Boletim surgiu da necessidade de estabelecer uma ponte de comunicação [...] com a comunidade externa», estabelecendo uma linha editorial centrada em informes, cursos, trabalhos e assuntos de interesses ligados ao Departamento de Estruturas e/ou programação de extensão voltadas para profissionais de engenharia Civil externos à UFPI.

Entende-se, portanto, que mesmo percebendo a efemeridade da primeira e única edição do Boletim Informativo do Departamento de Estruturas, e da maneira como foi concebido, de forma discreta, é perceptível sua contribuição no sentido de influenciar na formação continuada ou na prática de ensino do corpo docente do CT/UFPI. Ressalta-se, pois, a importância deste tipo de publicação como fonte para o estudo da História da Educação.

\section{Referências}

Cardoso, Magnaldo de Sá (20I7) O Centro de Tecnologia da UfPI: trajetória histórica. Teresina: EDUFPI.

CATANi, Denise Barbara (20I3) A imprensa periódica pedagógica e a história dos estudos educacionais no Brasil. In J. M. Hernández Díaz (org.) Prensa pedagógica y patrimonio histórico educativo, vol. I (pp. II5-I2I). Salamanca: Universidad de Salamanca. Colección Aquilafuente, 2013 .

Fávero, M. L. A. (2000) Universidade e Poder. Análise Crítica/Fundamentos Históricos (193045). 2. ed. Brasília: Plano.

Nunes, Clarice (1990) História da Educação: espaço do desejo. Em Aberto, Brasília, Ano 9, n. 47, pp. 37-45, jul./set. 1990 .

Universidade Federal do Piauí (1975) Resolução 18/75. Dispõe sobre a reestruturação do Centro de Tecnologia e dá outras providências. Teresina (PI): UfPI. 
